\title{
As relações CTSA nos anos iniciais do Ensino Fundamental: analisando a produção acadêmica e os livros didáticos
}

\author{
The CTSA relationships in the early years of Elementary School: \\ analyzing academic production and textbooks
}

\author{
Sandra Godoi Maestrelli ${ }^{1}$ \\ Leonir Lorenzetti ${ }^{2}$
}

\begin{abstract}
Resumo
Este artigo objetiva analisar as relações Ciência, Tecnologia e Sociedade (CTS) nos anos iniciais do Ensino Fundamental a partir dos trabalhos apresentados nas dez ediç̃̃es do Encontro Nacional de Pesquisa em Educação em Ciências (ENPEC), no período compreendido entre 1997 e 2015, e em periódicos da área de Educação em Ciências, no período de 2005 a 2015, relacionando com a ocorrência da abordagem Ciência, Tecnologia, Sociedade e Ambiente (CTSA) presente nos cinco livros didáticos de Ciências do $4^{\circ}$ ano do Ensino Fundamental mais distribuídos pelo Programa Nacional do Livro Didático (PNLD) para o ano de 2016, que abordam a temática água. A metodologia utilizada foi a pesquisa documental, de natureza quanti-qualitativa. A investigação contemplou o problema de pesquisa, a metodologia, as contribuições dos trabalhos, além da identificação, caracterização, quantificação e análise de diversos indicadores CTSA. Os resultados indicam que a abordagem das relações CTS ainda é escassa, tanto nas produções acadêmicas quanto nas produções didático pedagógicas, mesmo se considerarmos o número reduzido de artigos e livros selecionados para avaliação. Entretanto, os trabalhos que abordam o tema apresentam contribuições significativas para a Educação em Ciências, demonstrando a importância dessa abordagem para a Educação Básica.
\end{abstract}

Palavras-chave: CTSA; pesquisas acadêmicas; livro didático; anos iniciais; educação em ciências.

\section{Abstract}

This paper aims to analyze the Science, Technology and Society (STS) relations in the early years of Elementary School from the papers presented in the ten editions of the National Meeting of Research in Science Education (NMRSE), in the period between 1997 and 2015, and in periodicals of the area of Education in Related to the occurrence of the Science, Technology, Society and Environment (STSE) approach present in the five Science textbooks of the 4th year of elementary school, more distributed by the National Textbook Program (NTP) for the year 2016, which the water theme. The methodology used was documental research, of a quanti-qualitative nature. The research contemplated the research problem, the methodology, the contributions of the works, besides the identification, characterization, quantification and analysis of several STSE indicators. The results indicate that the STS relations approach is still scarce, both in academic productions and in didactic pedagogical productions, even considering the reduced number of articles and books selected for evaluation. However, the works that approach the theme present significant contributions to Science Education, demonstrating the importance of this approach for Basic Education.

Keywords: STSE; academic research; textbooks; early years; science education.

2 Universidade Federal do Paraná - UFPR | leonirlorenzetti22@gmail.com 


\section{Introdução}

Pesquisas recentes enfatizam a importância da abordagem Ciência, Tecnologia e Sociedade (CTS) para a Educação em Ciências. A cada ano aumenta o número de trabalhos que investigam esta temática na educação brasileira. (STRIEDER; KAWAMURA, 2009; ABREU; FERNANDES; MARTINS, 2013; MIRANDA, 2013a; MIRANDA, 2013b; FREITAS; GHEDIN, 2015; SOUSA; BRITO, 2015; STRIEDER et al. 2016).

Abreu, Fernandes e Martins (2013, p. 22) demonstraram em sua investigação que "as linhas de pesquisa em CTS/CTSA estão passando por um processo de expansão quantitativo dentro do campo de pesquisa em ensino de ciências". No entanto, verificaram um crescimento maior da produção acadêmica nas atas dos Encontros de Pesquisa na área de Ensino de Ciências do que nos periódicos relativos a esse campo de estudo. Observa-se ainda que os autores não conseguiram encontrar diferenças epistemológicas, filosóficas ou metodológicas entre os trabalhos que se declaravam CTS ou CTSA.

Segundo Santos (2012) os estudos CTS têm sido desenvolvidos no campo da sociologia, de políticas públicas e da educação. No ensino de ciências, a educação CTS é caracterizada pelas inter-relações entre os elementos da tríade - ciência, tecnologia e sociedade -, e pela interseção de propósitos entre o ensino de ciências, a educação tecnológica e a educação para a cidadania no sentido da participação na sociedade.

Nesse sentido, o enfoque CTS funciona como uma força cultural que é capaz de induzir à participação mais ativa de todos os cidadãos contribuindo para uma sociedade de melhor qualidade democrática, onde o caminho da mudança e do progresso passa por um modelo misto de princípios e ações. As práticas pedagógicas devem levar os alunos a discutir os problemas que a humanidade enfrenta em escala global, devendo, sobretudo, resultar em formas de ação com maior conhecimento e solidariedade. (MARTINS; PAIXÃO, 2011).

Não obstante a isso, a abordagem de ensino CTSA é essencial para a Educação em Ciências, pois oportuniza reflexões críticas sobre questões relacionadas à Ciência, Tecnologia, Sociedade e Ambiente, além de auxiliar no processo de tomada de decisões responsáveis para solução de problemas da nossa sociedade. (SANTOS; MORTIMER, 2002; SASSERON; CARVALHO, 2007; FARIAS; MIRANDA; PEREIRA FILHO, 2012).

Dessa forma, o objetivo principal da educação CTSA é ampliar os mecanismos de participação, contribuindo para potencializar o processo de tomada de decisão, desenvolvendo nos alunos um senso de responsabilidade para os problemas sociais e ambientais, tanto atuais quanto futuros. Nessa perspectiva, a ação social nos cursos CTSA incorpora o mesmo ideal das propostas curriculares de educação ambiental. (SANTOS; MORTIMER, 2002; SASSERON; CARVALHO, 2007; AULER, 2011, SANTOS, 2013).

Em outras palavras, pode-se dizer que o objetivo principal dos currículos CTS é o desenvolvimento da capacidade de tomada de decisão. Já o objetivo central do movimento CTSA acrescenta aos propósitos de CTS a ênfase em questões ambientais, visando a promoção da educação ambiental. (SANTOS, 2007, p. 2).

Santos e Mortimer (2002) esclarecem que, desde a década de 60 do século XX, currículos de ensino de ciências com ênfase nas relações CTS vêm sendo desenvolvidos em todo o mundo. Tais currículos apresentam como objetivo central a formação de cidadãos 
para o processo de tomada decisões e caracterizam-se por uma abordagem de conteúdos científicos no seu contexto social.

Ainda de acordo com os autores, a tomada de decisões é vista como um processo racional que envolve várias etapas. Estas etapas podem ocorrer em diferentes fases com diferentes níveis de complexidade. Portanto, não existe um modelo único de tomada de decisão, pois existe uma variedade de métodos nos quais os processos apresentam-se com passos e ações diferenciadas. O processo de tomada de decisões envolve situações típicas do dia a dia, nas quais as pessoas deparam-se com muitos acontecimentos e necessitam considerar não só os aspectos práticos e econômicos, mas também os sociais, ambientais e éticos:

As pessoas, por exemplo, lidam diariamente com dezenas de produtos químicos e têm que decidir qual devem consumir e como fazê-lo. Essa decisão poderia ser tomada levando-se em conta não só a eficiência dos produtos para os fins que se desejam, mas também os seus efeitos sobre a saúde, os seus efeitos ambientais, o seu valor econômico, as questões éticas relacionadas a sua produção e comercialização. Por exemplo, poderia ser considerado pelo cidadão, na hora de consumir determinado produto, se, na sua produção, é usada mão-de-obra infantil ou se os trabalhadores são explorados de maneira desumana; se, em alguma fase da produção ao descarte, o produto agride o ambiente; se ele é objeto de contrabando ou de outra contravenção, etc. Certamente o cidadão não tem acesso a todas essas informações, mas refletir sobre tais questões significa mudar a postura em relação ao consumo de mercadorias, pois, em geral, na maioria das vezes, a decisão entre consumir um ou outro produto é tomada em função de sua aparência e qualidade, e quase nunca são considerados os aspectos sociais, ambientais e éticos envolvidos na sua produção. Considerações de tal ordem poderiam, por exemplo, resultar na diminuição, a longo prazo, do consumo de embalagens descartáveis, de produtos que agridem a camada de ozônio, etc., forçando uma reformulação drástica nos processos de fabricação. (SANTOS; MORTIMER, 2002, p. 114).

Sendo assim, as ações mostradas acima exigem uma postura diferente que deve ser desenvolvida ao longo do tempo, como uma atitude cuidadosa, consciente e compromissada com os valores. É por esta razão que o processo de tomada de decisão nos anos iniciais do Ensino Fundamental deve ser estruturado a partir de três passos: conscientização, instrumentalização e desenvolvimento de um repertório atitudinal.

Lorenzetti (2000) parte da compreensão que os primeiros anos do Ensino Fundamental constituem o período de instrumentalização dos indivíduos para a compreensão do mundo em que vivem. De acordo com o autor, é neste período que as crianças estabelecem a compreensão inicial da ciência, desenvolvendo habilidades e atitudes científicas. Desta forma, os alunos terão os conhecimentos e elementos necessários para uma tomada de posição.

As orientações contidas nos Parâmetros Curriculares Nacionais contribuem para esse entendimento ao criticar um ensino de ciências puramente transmissivo, onde a exposição de conceitos, fatos e princípios é predominante. Por isso, os conteúdos curriculares devem incluir também conteúdos procedimentais e atitudinais. Os conteúdos procedimentais são aqueles que permitem a investigação, a comunicação e o debate de fatos e ideias, ou seja, 
que permitem a aprendizagem de ações específicas. Já os conteúdos atitudinais referem-se ao desenvolvimento de posturas e valores humanos, na relação entre o homem, o conhecimento e o ambiente. (BRASIL, 1997).

A educação CTSA é nova no Brasil e apesar de ser designada por alguns autores como uma "experiência restrita a um pequeno grupo de educadores", eles mesmos reconhecem que alguns documentos do Ministério da Educação começaram a incorporar este enfoque. Para as autoras, tal fato ocorre concomitantemente com o desenvolvimento, a partir dos mesmos documentos norteadores, do Enfoque das Competências, com as propostas de contextualização e interdisciplinaridade. (INVERNIZZI; FRAGA, 2007).

Para Castro et al. (2007, p. 3):

Mais que um método ou uma abordagem de ensino, esse movimento remete à reflexão sobre os sentidos de se ensinar ciências num mundo cada vez mais permeado pela tecnologia, pelo acúmulo da produção de informações, pela rapidez com que estas são socializadas e descartadas e pela participação dos cidadãos comuns nos debates de interesse coletivo. Em outras palavras, a ciência, a tecnologia e suas relações com a sociedade saturam nosso dia a dia e se impõem como formas de viver e de pensar. Algumas vezes, nos sentimos maravilhados com os desenvolvimentos em C\&T, outras, ameaçados por elas.

Assim, considerando a importância dos Estudos que envolvem a Ciência, Tecnologia, Sociedade e Ambiente, elencamos o seguinte problema de pesquisa: quais são as características dos trabalhos apresentados no ENPEC, no período de 1997 a 2015, que discutem CTS e CTSA e como esta abordagem é apresentada em Livros de Didáticos de Ciências, particularmente na temática água?

\section{Metodologia}

O trabalho está dividido em dois momentos. Inicialmente analisamos os trabalhos apresentados no Encontro Nacional de Pesquisa em Educação em Ciências (ENPEC) e trabalhos publicados em periódicos nacionais e, posteriormente, verificamos como a abordagem CTSA está presente nos livros didáticos, particularmente com relação à temática água. Para tanto, neste estudo, foi utilizada pesquisa de natureza qualitativa (GÜNTHER, 2006) do tipo documental. (GIL, 1999).

A busca dos trabalhos ocorreu no final do segundo semestre de 2015, primeiramente com uma pesquisa nas atas das dez edições do ENPEC ${ }^{3}$. Posteriormente, foram realizadas pesquisas nos periódicos nacionais: Ciência \& Educação, Ensaio: Pesquisa em Educação em Ciências, Investigações em Ensino de Ciências, Revista Brasileira de Pesquisa em Educação em Ciências, Revista Brasileira de Ensino de Ciências e Tecnologia, Ciência \& Ensino, Ciência e Educação, Revista EDUCAmazônia, Revista Dynamis, Revista Espacios de Gestão Tecnológica e Revista Atos de Pesquisa em Educação. Na esfera internacional, investigou-se a Revista Enseñanza de Las Ciências.

\footnotetext{
${ }^{3}$ Disponíveis em http://abrapecnet.org.br/wordpress/pt/atas-dos-enpecs
} 
O critério de seleção dos periódicos considerou os artigos publicados nos últimos dez anos (2005 a 2015). Para a busca dos artigos foram utilizadas as palavras-chave: CTS, CTSA, anos iniciais e Ensino Fundamental. Após a identificação dos trabalhos, verificou-se a adequação de cada um com a temática pesquisada para fins de categorização. Para tanto, foi realizada uma leitura dos resumos que continham tais termos, sendo que em alguns trabalhos, devido à ausência de informações, foi realizada leitura na íntegra.

Na primeira etapa, fez-se o levantamento dos trabalhos dos ENPECs e a identificação da abordagem de ensino privilegiada nas pesquisas. A segunda etapa compreendeu a realização de buscas em periódicos científicos, a fim de ampliar o panorama da área. A terceira etapa compreendeu a caracterização dos 14 artigos que foram selecionados para análise. Dos 14 trabalhos analisados, 5 foram apresentados em edições do ENPEC e 9 foram publicados em periódicos.

No segundo momento, foi analisada a ocorrência da abordagem CTSA a partir da temática água, em livros didáticos de Ciências do $4^{\circ}$ ano do Ensino Fundamental distribuídos pelo Programa Nacional do Livro Didático (PNLD), no ano de 2016. O critério de seleção considerou os cinco livros mais distribuídos pelo programa, conforme Tabela 1:

Tabela 1: Cinco livros didáticos de Ciências mais distribuídos pelo Programa Nacional do Livro Didático (PNLD) do ano de 2016

\begin{tabular}{|c|l|}
\hline $\begin{array}{c}\text { Código de } \\
\text { Identificação CI }\end{array}$ & \multicolumn{1}{|c|}{ Referência } \\
\hline LD1 & NIGRO, R.G. Projeto Ápis: Ciências. 2. ed., São Paulo: Ática, 2014. \\
\hline LD2 & BAKRI, M.S. Projeto Buriti: Ciências. 3. ed., São Paulo: Moderna, 2014. \\
\hline LD3 & CARNEVALLE, M.R. Ligados.com Ciências. São Paulo: Saraiva, 2014. \\
\hline LD4 & $\begin{array}{l}\text { MENDONÇA, F.B. Aprender juntos: Ciências. 4. ed., São Paulo: Edições SM, } \\
2014 .\end{array}$ \\
\hline LD5 & $\begin{array}{l}\text { PESSÔA, K.A.; FAVALLI, L. A escola é nossa: Ciências. 3. ed., São Paulo: } \\
\text { Scipione, 2014. }\end{array}$ \\
\hline
\end{tabular}

Os livros LD2 e LD3 foram excluídos da análise por não apresentarem um capítulo específico sobre o conteúdo analisado.

Para efeito de categorização das obras, adotou-se como referência os indicadores propostos por Fracalanza e Megid-Neto (2006) e adaptados por Amaral, Xavier e Maciel (2009). Ressalta-se que esses mesmos parâmetros já foram utilizados por Sepini, Cabral e Maciel (2013), no entanto, especificamente neste estudo, eles foram ampliados (tabela 2) e quantificados (tabela 3), de modo a contemplar uma investigação mais criteriosa dos pressupostos da abordagem CTSA. De modo a facilitar o entendimento sobre a presença dos indicadores citados abaixo, cada um deles será analisado separadamente nas três obras investigadas. Os indicadores I3, I5, I6, I7, I8 e I9 não foram detectados em nenhum dos livros, mas serão citados, indicando a sua importância para o ensino de ciências. 
Tabela 2: Indicadores CTSA - Relações Ciência, Tecnologia, Sociedade e Ambiente

\begin{tabular}{|c|l|}
\hline Indicadores & \multicolumn{1}{|c|}{ Descrição dos indicadores } \\
\hline I1 & $\begin{array}{l}\text { Contextualiza historicamente o processo de produção do conhecimento } \\
\text { científico. }\end{array}$ \\
\hline I2 & Aborda a aplicação pela sociedade do conhecimento científico. \\
\hline I3 & Discute os impactos decorrentes da aplicação do conhecimento científico. \\
\hline I4 & Aborda o conhecimento científico como base ao desenvolvimento tecnológico. \\
\hline I5 & $\begin{array}{l}\text { Aborda o conhecimento tecnológico como fornecedor de técnicas para o } \\
\text { desenvolvimento científico. }\end{array}$ \\
\hline I6 & Aborda a tecnologia como fator para melhorias das condições de vida. \\
\hline I7 & Aponta outros fins para a tecnologia (bélicos, lucro, etc.). \\
\hline I8 & Evita abordar a CT como potencialmente solucionadoras de qualquer problema. \\
\hline I9 & Aborda os elementos curriculares CTSA e suas inter-relações. \\
\hline I10 & Aborda conceitos científicos e tecnológicos \\
\hline I11 & Aborda processos de investigação. \\
\hline I12 & O conteúdo é definido em função do tema/problema. \\
\hline I13 & Estuda as questões ambientais definidas em função do tema/problema. \\
\hline I14 & Retoma a discussão da questão original. \\
\hline
\end{tabular}

Fonte: Fracalanza e Megid-Neto (2006) adaptados por Amaral, Xavier e Maciel (2009).

\section{A abordagem das relações CTS nos anos iniciais do Ensino Fundamental}

O levantamento dos trabalhos do ENPEC mostrou que somente no ano de 2003 foi apresentado o primeiro trabalho com a temática CTS nos anos iniciais, sendo que os demais foram apresentados nos anos de 2007, 2011, 2013 e 2015. Com relação à abordagem CTSA, destaca-se que apenas um trabalho foi localizado.

Já na investigação dos periódicos, os resultados mostraram que foi somente em 2005 que se iniciaram as discussões sobre CTS nos anos iniciais. Desse modo, foram encontrados um artigo na Revista Ciência \& Educação, no ano de 2005; três artigos na Revista Investigações em Ensino de Ciências, sendo o primeiro em 2008 e os últimos dois no ano de 2013; dois artigos na Revista EDUCAmazônia, em 2013 e 2014; um artigo na Revista Dynamis, em 2013; um artigo na Revista Espacios de Gestão Tecnológica, em 2014; e um artigo na Revista Atos de Pesquisa em Educação, em 2012.

Dos 14 trabalhos sobre CTS indicados acima, 6 direcionaram os olhares para o coletivo dos alunos, 5 trabalhos investigaram o coletivo dos professores e somente 3 trabalhos priorizaram o coletivo de alunos e professores.

Referente às pesquisas que priorizaram os olhares para o coletivo dos estudantes, Sasseron e Carvalho (2007; 2008) investigaram como a abordagem de ensino CTSA pode auxiliar na Alfabetização Científica (AC) dos alunos dos anos iniciais do Ensino Fundamental. As autoras verificaram indícios da alfabetização científica por meio das discussões sobre as relações CTSA. Do mesmo modo, Fabri e Silveira (2013) pesquisaram como a abordagem CTS pode auxiliar na Alfabetização Científica e Tecnológica (ACT) dos alunos. Para tanto, utilizaram uma sequência didática partindo do eixo temático Recursos Tecnológicos. 0 trabalho manteve a estrutura disciplinar sem alterações no currículo e houve enxerto de temas sociocientíficos. Viecheneski e Carletto (2013) também analisaram as contribuições de 
uma sequência didática para alunos dos primeiros anos do Ensino Fundamental. As autoras partiram do pressuposto de que as orientações epistemológicas do enfoque (CTS) contribuem para a AC das crianças, como também, propiciam às atividades de leitura e escrita maior contextualização e significado. Utilizaram um tema sociocientífico (alimentação humana) para construir o conhecimento científico. Magno e Almeida (2015) retrataram uma estratégia de ensino por meio de atividades lúdicas que empregam a abordagem CTS mediante temas, com o objetivo de investigar a potencialidade dessa associação no processo de ensino aprendizagem de estudantes da Educação básica. Utilizaram o tema "meio de transportes", que surgiu durante uma atividade anterior com o jogo de tabuleiro "semáforo".

No coletivo dos professores, Teixeira e Cicillini (2003) verificaram como a noção de cidadania tem sido construída a partir das práticas de professores de Ciências do Ensino Fundamental no desenvolvimento de conteúdos relacionados aos temas de Educação e Saúde, Educação Ambiental e CTS, considerando as contribuições destas temáticas para a formação do aluno cidadão. Viecheneski e Carletto (2011) examinaram como os educadores vêm trabalhando o Ensino de Ciências nos primeiros anos do Ensino Fundamental. As autoras apontaram a necessidade de se buscar novas abordagens para o ensino de Ciências, destacando-se na literatura estrangeira e nacional o enfoque CTS. Fabri, Silveira e Niezer (2014) apresentaram os resultados de uma oficina oferecida aos docentes dos anos iniciais, a qual teve como propósito trabalhar o ensino de ciências em um enfoque (CTS). Ferst e Silva (2014) analisaram como se constrói o processo de ensinar e qual a formação docente necessária para o professor a fim de promover reflexões sobre a teoria de Feyerabend no ensino de Ciências, abordando suas principais contribuições e a atuação do professor frente a esta abordagem e os norteadores da CTS. Ferst (2013) verificou como estão as pesquisas referentes à formação de professores em CTS, com destaque para as propostas de atividades didático-pedagógicas em CTS.

No que concerne às pesquisas para o coletivo dos alunos e professores, foram encontrados três trabalhos, nos quais: Viecheneski, Lorenzetti e Carletto (2012) problematizaram o ensino de Ciências nos anos iniciais do Ensino Fundamental. Discutiram a necessidade de não só se buscar novas abordagens para o ensino de Ciências, mas também, de estimular os docentes a refletirem sobre as concepções que possuem sobre Educação, Ciência e Tecnologia. Utilizaram o tema "lixo" para favorecer uma abordagem de ensino contextualizada e potencialmente rica em possibilidades de articulação entre conhecimentos de diversas áreas. Concluíram que a AC, por meio do enfoque CTS, emerge como uma alternativa viável à formação de todos os cidadãos. Vieira e Vieira (2005) investigaram como o programa de formação de professores e desenvolvimento de materiais didáticos pode auxiliar na promoção da "Literacia Científica" e nas práticas de educação CTS, em Portugal. Optaram por desenvolver materiais didáticos CTS tendo por base o tema "As plantas: sua utilização em atividades humanas". Lima e Junior (2013) desenvolveram uma sequência didática sobre a temática "poluição" a partir do enfoque CTS. Realizaram estudos teóricos e discussões dirigidas com o objetivo de promover a melhoria social dos moradores de um bairro que circunda o Campus Universitário da Universidade Estadual de Londrina.

A partir dos dados, constata-se que a produção analisada não apresenta muita dispersão em relação aos autores. Viecheneski e Carletto apresentam quatro publicações, seguidos com Ferst, Fabri e Silveira e Sasseron e Carvalho, todos com dois trabalhos. 
Evidencia-se que esses trabalhos são decorrentes das dissertações de mestrado de Viecheneski e Fabri e das teses de doutorado de Ferst e Sasseron. Portanto, apesar da relevância comprovada da educação CTS, a produção acadêmica nos primeiros anos da educação básica ainda é escassa. Como consequência a CTS e a CTSA ainda são pouco conhecidas nesta etapa de ensino. As investigações mostram que, além da pouca produção acadêmica na área, o problema pode estar relacionado com uma série de outros fatores, tais como: falta de políticas públicas, precariedade na formação inicial e continuada de professores, ausência de propostas pedagógicas e até mesmo desconhecimento do termo CTSA pelos professores. "Embora o movimento CTS tenha sido bastante difundido em outros países, no Brasil não tivemos a oportunidade de contar com um programa nacional de orientação nesse sentido". (BERNARDO; VIANNA; SILVA, 2011, p. 374). Essa ideia é corroborada por Azevedo et al (2013) que afirmam que a formação de professores, pelos problemas apresentados em seus aspectos teórico-epistemológicos e éticos, é o principal obstáculo à inserção do enfoque CTS no processo educacional.

\section{A abordagem CTSA nos livros didáticos de ciências}

Dos três livros didáticos analisados, o LD1 foi o que apresentou maior número de indicadores CTSA, oito no total, seguido pelo livro LD4 com sete indicadores e pelo LD5 com seis indicadores. No entanto, a presença destes indicadores nos livros revela não haver muita dispersão na forma de abordar o conteúdo. Este fato é preocupante, pois em cada obra analisada percebe-se um conteúdo diferente sobre água, que pode apresentar maior ou menor potencial para o desenvolvimento da abordagem CTSA.

Com base nas análises realizadas foi possível identificar os seguintes indicadores, conforme tabela 3.

Tabela 3: Presença dos Indicadores CTSA - Relações Ciência, Tecnologia, Sociedade e Ambiente

\begin{tabular}{|c|c|c|c|c|c|c|c|c|c|c|c|c|c|c|c|}
\hline $\begin{array}{l}\text { Código de } \\
\text { Identificação }\end{array}$ & \multicolumn{14}{|c|}{ Indicadores CTSA } & Qtde \\
\hline $\mathrm{CI}$ & I1 & I2 & I3 & I4 & I5 & I6 & I7 & I8 & 19 & $\mathrm{I} 10$ & I11 & $\mathrm{I} 12$ & $\mathrm{I} 13$ & I14 & Total \\
\hline LD1 & 1 & 1 & - & 2 & - & - & - & - & - & 19 & 9 & $x$ & 4 & 7 & 43 \\
\hline LD4 & 2 & - & - & 2 & - & - & - & - & - & 21 & 3 & $X$ & 4 & 4 & 36 \\
\hline LD5 & - & - & - & 2 & - & - & - & - & - & 18 & 2 & $X$ & 4 & 1 & 27 \\
\hline Total & 3 & 1 & - & 6 & - & - & - & - & - & 58 & 14 & $X$ & 12 & 12 & 106 \\
\hline
\end{tabular}

Com relação ao número de ocorrências de cada indicador, o livro LD1 também é o que apresenta o maior resultado: $41 \%$ do total. No comparativo com as outras obras, percebese que a quantidade de ocorrências no livro LD1 é 7\% maior que no livro LD4 e 16\% maior que no livro LD5. No entanto, destaca-se que o livro DL1 apresenta uma unidade inteira sobre o conteúdo da água, contendo três capítulos e 30 páginas, diferente do livro LD4, em que o conteúdo está contemplado em apenas um capítulo.

No livro LD1, os conteúdos conceituais estão apresentados em três capítulos completos, com conteúdos relacionados entre si. São espaços reservados ao desenvolvimento do trabalho com conceitos, proposições conceituais, procedimentais e atitudinais. A unidade que trata da água traz o tema "água, solo e ser humano" composto pelos capítulos: o solo e sua ocupação, cuidando do solo e de suas águas, água em casa. 
Já o livro LD4 contém quatro unidades organizadas em temas, cada uma com três capítulos. O conteúdo da água está contemplado no capítulo dois, que é composto por: estados físicos da água, misturas com água, onde está a água, o ciclo da água.

No livro LD5 a unidade também está pautada em temas: água em nosso planeta, estados físicos da água, os estados físicos da água no ambiente, mudanças de estados físicos da água, o ciclo da água no ambiente, água como solvente, separação de substâncias presentes na água.

Em relação ao indicador I1, que trata da contextualização histórica do processo de produção do conhecimento científico, percebe-se a presença do mesmo nos livros LD1 e LD4, conforme exemplos abaixo:

Os moinhos de antigamente eram movidos por fontes naturais de energia. Por exemplo, podia-se usar a força muscular de pessoas ou animais para movimentar pedras que, com seu peso, amassavam e moíam os grãos. Mas também podia-se usar a força do movimento da água. Os primeiros moinhos de água funcionavam com a força da correnteza da água que incidia na parte inferior de uma roda-d'água e a fazia girar. [...] (LD1, 2014, p. 151).

Por que a água do mar é salgada? Um pouco dos sais minerais que existem nas rochas é dissolvido pela água das chuvas e dos rios. Esses sais são levados para os oceanos quando os rios deságuam. Os cientistas acreditam que, ao longo de milhões de anos, os sais se acumularam nos oceanos, tornando-os salgados. Também é possível que parte do sal dos oceanos tenha se originado da lava de vulcões que existem no fundo do mar. (LD4, 2014, p. 30).

O indicador I2, que aborda a aplicação pela sociedade do conhecimento científico, foi localizado apenas no livro LD1, conforme trecho abaixo:

[...] num morro, quanto mais íngreme for sua encosta, mais rápido e com mais força a água vai escorrer, arrastando com ela partículas de terra. É a água promovendo a erosão do solo. Mas todo esse efeito da água pode ser diminuído. Você sabe como? Quando uma montanha possui curvas de nível, a força da água que escorre é reduzida. Com isso, a erosão causada pela água será menor. É por isso que são feitas curvas de nível em áreas de encosta: antes da construção de casas e edifícios; na beira de rodovias; nas plantações. (LD1, 2014, p. 56).

Convém salientar que os estudos das aplicações da ciência e tecnologia devem explorar as dimensões sociais, de modo que o aluno seja capaz de compreender o que é ciência e tecnologia, evitando assim, o desenvolvimento de uma visão deformada da natureza destes conhecimentos. É importante ter a compreensão de que, tanto a ciência como a tecnologia escondem interesses econômicos que visam manter a atual conjuntura dos acontecimentos. (SANTOS; MORTIMER, 2002).

O indicador I3, que discute os impactos decorrentes da aplicação do conhecimento científico, não foi localizado em nenhuma das obras. Rosenthal (1989 apud SANTOS; MORTIMER, 2002) apresenta uma série de aspectos relativos a ciências que poderiam ser abordados nos currículos, como questões de natureza filosófica - que incluiriam, entre 
outros, aspectos éticos do trabalho científico, o impacto das descobertas científicas sobre a sociedade e a responsabilidade social dos cientistas no exercício de suas atividades.

Com relação ao indicador I4, que aborda o conhecimento científico como base ao desenvolvimento tecnológico, o mesmo foi encontrado em todas as obras, no entanto, por questões de natureza sintética, apenas dois livros foram escolhidos para exemplificar este descritor:

Nas salinas, a água do mar fica em reservatórios grandes e rasos, expostos ao sol e ao vento. Após a evaporação de quase toda a água, resta o sal no fundo do reservatório. Esse processo serve, por exemplo, para a obtenção do sal de cozinha. (LD4, 2014, p. 27).

A filtração é uma técnica utilizada na separação de substâncias que não se dissolvem na água. Para realizá-la, a mistura é colocada em um filtro que retém a maior parte dos materiais e deixa passar a parte líquida. $O$ filtro caseiro é utilizado para reter, ou seja, não deixar passar algumas impurezas da água que bebemos. (LD5, 2014, p. 75).

Por outro lado, o indicador I5, que aborda o conhecimento tecnológico como fornecedor de técnicas para o desenvolvimento científico, não está presente em nenhuma das obras, fato que evidencia a ausência das discussões sobre a disponibilidade dos recursos tecnológicos, a qual pode limitar ou ampliar os progressos científicos. (MCKAVANAGH; MAHER, 1982 apud SANTOS; MORTIMER, 2002).

Do mesmo modo, a ausência do indicador I6 que aborda a tecnologia como fator para melhorias das condições de vida e do indicador I7, que aponta outros fins para a tecnologia (bélicos, lucro, etc.) demonstra que as discussões sobre os benefícios e malefícios da tecnologia não foram contempladas nas obras, o que ressalta a escassez de reflexões sobre os efeitos que a tecnologia pode causar na sociedade ou na ciência.

No que se refere à discussão sobre a perspectiva salvacionista de ciência, proposta no indicador I8, observou-se sua inexistência nas obras. Esta perspectiva faz parte, segundo Auler (2002), do modelo tradicional/linear de progresso, que pode ser considerada como um mito e deve ser problematizada ou superada tanto por alunos como professores.

O descritor 19, que aborda os elementos curriculares CTSA e suas inter-relações, não foi localizado nas obras. Para Sasseron e Carvalho (2007), o objetivo da educação CTSA está diretamente relacionado com a construção de um futuro sustentável para a sociedade e o planeta. As autoras partem da compreensão que o entendimento das relações existentes entre ciência, tecnologia, sociedade e meio ambiente pode auxiliar na resolução de problemas ambientais que estão estreitamente vinculados entre si.

Por outro lado, tal como esperado, o indicador I10, que aborda conceitos científicos e tecnológicos, aparece diversas vezes em todos os livros analisados, no entanto, por questões de natureza sintética, apenas um trecho de cada livro foi escolhido para exemplificar esse parâmetro:

Ao contrário do que parece, a água cristalina e inodora que brota nas fontes naturais de alguns parques e praças de Curitiba não serve para o consumo humano. De acordo com a Secretaria Municipal de Saúde, a maior parte delas está contaminada por coliformes fecais (tipos de bactérias presentes no intestino de diferentes seres vivos). (LD1, 2014, p. 67). 
A água é considerada um bom solvente porque dissolve vários materiais, como o açúcar. Os materiais que se dissolvem na água são solúveis. Alguns materiais apresentam maior facilidade em se dissolver, enquanto outros são menos solúveis. No exemplo inicial do açúcar, após a dissolução em água, não é mais possível diferenciar os dois materiais, pois eles se misturaram e formaram uma solução. Solução é um líquido que contém substâncias dissolvidas. (LD4, 2014, p. 26).

A decantação é uma técnica que consiste em deixar a mistura em repouso para que grande parte da substância misturada à água se deposite no fundo do recipiente. A decantação é utilizada na separação de algumas substâncias que não se dissolvem na água. (LD5, 2014, p. 75).

O indicador I11, que aborda processos de investigação, também está presente em todas as obras, porém percebe-se que, em alguns casos, o método científico ainda é tratado como um conjunto de etapas padronizadas e rígidas, o que requer uma atenção maior do professor em relação a esse item.

No livro LD1 aparecem processos de investigação sobre o tema "água para consumo", em que se faz necessário observar, analisar, formular hipóteses, realizar o experimento e representar os conhecimentos obtidos. Esse processo foi utilizado em dois processos de separação de misturas: a decantação e a filtração. (LD1, 2014, p. 78).

De acordo com os Parâmetros Curriculares Nacionais (1997), os conteúdos para o ensino de ciências foram ampliados, de modo a priorizar o "fazer científico". Sendo assim, houve a incorporação dos conteúdos procedimentais que incluem os métodos investigativos com o desenvolvimento das habilidades citadas acima.

No livro LD4, a questão abaixo foi apresentada com o objetivo de realizar um experimento, no qual os alunos misturam água com gotas de corante e deixam evaporar sob o sol, para mostrar que no processo de evaporação a água é separada de todos os materiais que estão dissolvidos nela. (LD4, 2014, p. 30).

Por que a chuva na praia não é salgada? Você sabe que a água evapora e se condensa, formando as nuvens. No oceano isso também acontece. Então, por que na praia a água da chuva é doce? (LD4, 2014, p. 30).

Com relação ao livro LD5, na página 68, o conceito de estados físicos da água é ampliado com uma proposta de experimento realizado para verificar o que acontece com parte da água de um copo que permanece algumas horas em um local que recebe diretamente a luz solar. (LD5, 2014, p. 68).

Do mesmo modo, o indicador I12, que demonstra se o conteúdo é definido em função de um tema ou problema foi localizado em todos os livros. No livro DL1, "os conteúdos conceituais são apresentados em quatro unidades didáticas, cada uma com três capítulos. Sempre em páginas duplas, as aberturas possuem ilustrações que sugerem os temas que serão estudados nos capítulos, além de perguntas que promovem uma leitura inicial de tais imagens". (LD1, 2014, p. 201). Sendo assim, na unidade didática que apresenta o tema da água, solo e ser humano, o conteúdo é definido em função desses temas, os quais apresentam imagens e questões problematizadoras como forma de motivar e instigar os alunos para os assuntos apresentados.

Para exemplificar como esse descritor aparece no livro L4, foi escolhido um trecho explicativo sobre a organização e estrutura da coleção: "Para promover a articulação e a 
integração dos conteúdos, assim como a relação com a vivência e o cotidiano do aluno, cada volume da coleção está organizado em temas: ambiente, animais, plantas, ser humano e saúde, universo e energia". (LD4, 2014, p. 204).

Tal como ocorre nas outras obras, no livro LD5:

Cada volume é dividido em unidades que, por sua vez, são divididas em temas principais. [...] As unidades iniciam-se com uma seção que tem como principais objetivos resgatar os conhecimentos prévios dos alunos e apresentar informações sobre o conteúdo a ser estudado na unidade. Os recursos e as atividades sugeridos ao longo das unidades procuram abordar assuntos relacionados ao cotidiano dos alunos, permitindo a eles formular hipóteses. (LD5, 2014, p. 199-200).

No que se refere ao indicador I13, que verifica se o livro estuda as questões ambientais definidas em função do tema/problema, constatou-se sua presença nos três livros analisados, porém as discussões ainda são insuficientes. Um exemplo disso é uma notícia jornalística que discorre sobre os altos índices de poluentes no Aquífero Guarani em decorrência da prática da agricultura e pecuária: "O risco de contaminação [...] é preocupante, mas ainda não compromete para uso do homem os quase 50 quatrilhões de litros de água do aquífero". (LD4, 2014, p. 31).

No texto é possível notar que, apesar da discussão sobre a contaminação por agrotóxicos e produtos da pecuária, não existe uma reflexão mais aprofundada sobre os usos da água no Brasil e no mundo. O debate, presente em todos os livros, se limita a trazer o desperdício de água pelas pessoas, ou seja, apenas o uso doméstico da água, o que, na verdade, corresponde ao menor consumo.

[...] Quem vive em locais em que não há uma rede de esgotos deve construir uma fossa em sua casa. Ela serve para recolher o esgoto e pode ser de dois tipos: a seca (ou negra) e a séptica. Numa fossa seca os resíduos são jogados diretamente num buraco no solo. Isso pode contaminar as águas subterrâneas. Por isso é aconselhável construir uma fossa séptica. Na fossa séptica o esgoto não é liberado diretamente no solo, o que diminui os riscos de contaminação dos lençóis de água subterrâneos. (LD1, 2014. p. 68).

O livro LD5, na seção 'minhas ideias, nossas ideias', apresenta um texto que discorre sobre a intensificação do efeito estufa natural, conhecido como aquecimento global, bem como as consequências para o meio ambiente:

Um dos problemas do aquecimento global no meio ambiente é o derretimento das geleiras (calotas polares), principalmente as que estão situadas nos polos Ártico e Antártico. Como o passar do tempo, o derretimento das geleiras pode provocar o aumento do nível da água dos oceanos e muitos prejuízos aos ambientes onde vivem diversos animais, como os ursos-polares. (LD5, 2014, p. 67).

Com relação ao último indicador, que retoma a discussão da questão original, qual seja, "retoma a discussão da questão original" constata-se que todos os livros apresentam atividades de sistematização de conteúdos que foram abordados ao longo da unidade didática ou capítulo. No livro LD1, esse processo ocorre por meio da seção "Traçando saberes" e também com mapas conceituais, que constituem um bom recurso visual para 
sintetizar os principais conceitos e proposições trabalhados em cada unidade. (LD1, 2014, p. 209).

No livro LD4, a seção 'Agora já sei' apresenta atividades que resgatam e aplicam os conteúdos trabalhados. Na unidade que trata especificamente da água, a proposta é conversar com um colega para compartilhar o conhecimento sobre a formação das nuvens e as mudanças de estado envolvidas neste processo. (LD4, 2014, p. 32).

Já no livro LD5, a seção 'Retomando' objetiva confrontar os conhecimentos prévios dos alunos com os conhecimentos construídos ao estudar a unidade. Na unidade sobre a água, essa retomada é realizada a partir de questões elaboradas sobre cada conteúdo. (LD5, 2014, p. 79).

\section{Considerações Finais}

A partir dasanálises realizadas, percebe-se que a abordagem das relações CTSA ainda é escassa tanto nas produções acadêmicas quanto nos livros didáticos, mesmo se considerarmos o número reduzido de artigos e obras selecionadas para avaliação, bem como da análise da temática água.

Sendo assim, na investigação sobre as produções acadêmicas, dos 14 trabalhos selecionados, apenas um tratava da temática CTSA. Já na análise dos livros didáticos, dos 14 descritores investigados, apenas 8 indicadores CTSA foram localizados. Além deste fato, destaca-se que a presença de tais descritores não apresentou muita dispersão em relação às obras analisadas, ou seja, a forma de abordar o conteúdo ocorreu de maneira similar nos livros LD4 e LD5.

Todavia, não se pode discutir as relações CTSA sem evocar o papel do professor, uma vez que ele apresenta importante função no tratamento dos conteúdos, na aquisição de habilidades necessárias para a resolução dos problemas, bem como na condução das discussões de questões sociais relevantes, sejam elas de impacto local ou mundial. O estudo de Candéo, Silveira e Matos (2014) mostra como as concepções dos professores sobre ciência e tecnologia precisam ser ampliadas e como elas impactam nas compreensões sobre as relações sociais da ciência e da tecnologia

Nesse sentido, ressalta-se a importância dos cursos de formação continuada para que o docente seja capaz de desenvolver propostas de ensino nessa abordagem, mudando sua forma de pensar e agir na educação. O professor precisa estar disposto a aprender sempre, pois sempre surgirão novas tecnologias, novos recursos e novas estratégias de ensino, de modo que, na sua essência, o mesmo precisa se assumir como pesquisador.

Em suma, apesar da maior parte dos artigos selecionados para análise ter apresentado sequências didáticas como proposta de trabalho, é importante destacar que os livros didáticos de Ciências deveriam oferecer aos professores maiores oportunidades de promoção da abordagem CTSA, pois a incorporação de tais pressupostos depende também da sua presença nos manuais escolares.

É importante salientar que este artigo, limitado à análise da produção acadêmica e dos capítulos dos livros didáticos que abordam o conteúdo da água em determinado período, apesar de acrescentar novos elementos às discussões CTSA no contexto do ensino de Ciências, não comporta conclusões abrangentes a respeito de cada obra, quando considerada em sua totalidade. 
Por fim, cabe salientar que, apesar do pouco número de artigos e livros encontrados sobre a temática, os resultados demonstram que essa abordagem de ensino apresenta uma gama de possibilidades para o trabalho pedagógico. As articulações e aproximações com o cotidiano contribuem para os processos de ensino e aprendizagem de forma a propiciar a alfabetização científica dos alunos. Sendo assim, as concepções e propostas apresentadas neste estudo refletem consideravelmente o potencial da CTSA para a Educação em Ciências.

\section{Referências}

ABREU, T. B.; FERNANDES, J. P.; MARTINS, I. Levantamento sobre a produção CTS no Brasil no período de 1980-2008 no campo de ensino de Ciências. Alexandria Revista de Educação em Ciência e Tecnologia, Florianópolis, v. 6, n. 2, p. 3-32, jun. 2013.

AMARAL, C. L. C.; XAVIER, E. S.; MACIEL, M. D. Abordagem das Relações Ciência/Tecnologia/Sociedade nos Conteúdos de Funções Orgânicas em Livros Didáticos de Química do Ensino Médio. Investigações em Ensino de Ciências, Porto Alegre, v. 14, n. 1, p. 101-114, 2009.

AULER, D. Interações entre Ciência-Tecnologia-Sociedade no Contexto da Formação de Professores de Ciências. 2002. 257f. Tese. (Doutorado em Educação). Programa de PósGraduação em Educação, Universidade Federal de Santa Catarina, Florianópolis: CED/UFSC, 2002.

AULER, D. Novos caminhos para a educação CTS: ampliando a participação. In: SANTOS, W. L. P. dos; AULER, D. (Orgs). CTS e educação Científica: desafios, tendências e resultados de pesquisa. Brasília: Editora UnB, 2011. p. 73-97.

AZEVEDO, R. O. M. et al. Questões sociocientíficas com enfoque CTS na formação de professores de Ciências: perspectiva de complementaridade. Amazônia: Revista de Educação em Ciências e Matemática, v. 9, n. 18, p. 84-98, jan/jun, 2013.

BERNARDO, J. R. R.; VIANA, D. M.; SILVA, V. H. D. da; A construção de propostas de ensino em Ciência-Tecnologia-Sociedade (CTS) para abordagem de temas sociocientíficos. In: SANTOS, W. L. P.; AULER, D. (Orgs.) CTS e educação Científica: desafios, tendências e resultados de pesquisa. Brasília-DF: Editora UnB, 2011. p. 373-393.

BRASIL. Guia de Livros Didáticos PNLD 2016. Ensino Fundamental- Ciências. Brasília: MEC, 2014. Disponível em: http://www.fnde.gov.br/pnld-2016/ Acesso em: 10 dez. 2016.

BRASIL. Secretaria de Educação Fundamental. Parâmetros Curriculares Nacionais: Ciências Naturais. Brasília: MEC/SEF, 1997.

CANDÉO, M.; SILVEIRA, R. M. C. F.; MATOS, E. A. S. A. de Relações sociais da Ciência e da Tecnologia: percepções dos professores de formação técnica participantes do PARFOR. Amazônia: Revista de Educação em Ciências e Matemática, v. 11, n. 21, p. 79-91, jul/dez, 2014.

CASTRO, R.S. et al. CTSA: uma abordagem para enfrentar a complexidade do mundo contemporâneo. In: ENCONTRO NACIONAL DE PESQUISA EM EDUCAÇÃO EM CIÊNCIAS. VI. Anais... Florianópolis. 2007. 
FABRI, F.; SILVEIRA, R. M. C. F. O ensino de ciências nos anos iniciais do ensino fundamental sob a ótica CTS: uma proposta de trabalho diante dos artefatos tecnológicos que norteiam o cotidiano dos alunos. Revista Investigações em Ensino de Ciências, v.18, n.1, p. 77-105, 2013.

FABRI, F.; SILVEIRA, R. M. C. F.; NIEZER, T. M. Ensino de Ciências nos anos iniciais e a abordagem CTS: uma experiência pedagógica na formação de professores. Revista Espacios de Gestão Tecnológica, v. 35, n. 6, p. 9-23, 2014.

FARIAS, L. N.; MIRANDA, W. S.; PEREIRA FILHO, S. C. F. Fundamentos epistemológicos das relações CTS no ensino de ciências. Amazônia: Revista de Educação em Ciências e Matemática, v. 9, n. 17, p. 63-75, jul/dez, 2012.

FERST, E. M. A abordagem CTS no ensino de ciências naturais: possibilidades de inserção nos anos iniciais do Ensino Fundamental. Revista EDUCAmazônia - Educação Sociedade e Meio Ambiente, Humaitá, v. XI, n. 2, p. 276-299, dez. 2013.

FERST, E. M.; SILVA, M. C. F. Contribuições da epistemologia de Feyerabend para a discussão da abordagem CTS no ensino de ciências naturais no ensino fundamental. Revista EDUCAmazônia - Educação Sociedade e Meio Ambiente, Humaitá, v. XIII, n. 2, p. 95-114, jul/dez, 2014.

FRACALANZA, H.; MEGID NETO, J. (Org.). O Livro didático de Ciências no Brasil. Campinas: Komedi, 2006.

FREITAS; L. M.; GHEDIN, E. Pesquisas sobre Estado da Arte em CTS: análise comparativa com a produção em periódicos nacionais. Alexandria Revista de Educação em Ciência e Tecnologia, Florianópolis, v.8, n.3, p. 3-25, nov. 2015.

GIL, A.C. Métodos e técnicas de pesquisa social. 5 ed. São Paulo: Atlas, 1999.

GÜNTHER, H. Pesquisa Qualitativa Versus Pesquisa Quantitativa: Esta É a Questão? Psicologia: Teoria e Pesquisa, Brasília, v.22, n.2, p. 201-210, mai/ago. 2006.

INVERNIZZI, N.; FRAGA, L. Estado da arte na educação em ciência, tecnologia, sociedade e ambiente no Brasil. Revista Ciência \& Ensino, Piracicaba, v. 1, número especial, nov. 2007.

LIMA, J. M. M.; JUNIOR, A. L. Estudo do processo da elaboração de uma unidade didática sobre poluição. In: ENCONTRO NACIONAL DE PESQUISA EM EDUCAÇÃO EM CIÊNCIAS, IX, Águas de Lindóia. Anais..., Águas de Lindóia, 2013.

LORENZETTI, L. Alfabetização científica no contexto das séries iniciais. 144 f. Dissertação (Mestrado em Educação). Universidade Federal de Santa Catarina, Florianópolis, 2000.

MAGNO, C. M. V.; ALMEIDA, A. C. P. C. Ludicidade e CTS no ensino de Ciências na Educação Básica de Ribeirinhos na Amazônia. In: ENCONTRO NACIONAL DE PESQUISA EM EDUCAÇÃ̃ EM CIÊNCIAS. X, Águas de Lindóia. Anais..., Águas de Lindóia, 2015.

MARTINS, I. P.; PAIXÃO, M. D. F. Perspectivas atuais Ciência-Tecnologia-Sociedade no ensino e na investigação em educação em ciência. In: SANTOS, W. L. P. dos; AULER, D. (Orgs). CTS e educação Científica: desafios, tendências e resultados de pesquisa. Brasília-DF: Editora UnB, 2011. p. 135-160.

MIRANDA, E. M. Análise das principais tendências da perspectiva ciência, tecnologia e sociedade (CTS) em teses e dissertações brasileiras das áreas de educação e ensino de 
ciências. In: CONGRESSO INTERNACIONAL SOBRE INVESTIGACIÓN EM DIDÁCTICA DE LAS CIENCIAS, MIRANDA, IX., 2013, Girona. Comunicación..., 2013a. p. 2214-2218.

MIRANDA, E. M. Panorama das teses e dissertações brasileiras e portuguesas sobre educação ciência, tecnologia e sociedade. In: In: CONGRESSO INTERNACIONAL SOBRE INVESTIGACIÓN EM DIDÁCTICA DE LAS CIENCIAS, MIRANDA, IX., 2013, Girona. Comunicación..., 2013b. p. 2219-2224.

SANTOS, W. L. P. Contextualização no ensino de ciências por meio de temas CTS em uma perspectiva crítica. Revista Ciência \& Ensino, Piracicaba, v. 1, número especial, p. 1-12, 2007.

SANTOS, W. L. P. Educação científica sob abordagem CTS - ciência, tecnologia, sociedade: desafios, tendências e resultados de pesquisa. Brasília, 12 set. 2013. Palestra proferida na Universidade de Brasília- UNB.

SANTOS, W. L. P. Educação CTS e cidadania: confluências e diferenças. Amazônia: Revista de Educação em Ciências e Matemática, v. 9, n. 17, p. 49-62, jul/dez, 2012.

SANTOS, W. L. P.; MORTIMER, E. F. Uma análise dos pressupostos teóricos da abordagem C-T-S (Ciência-Tecnologia-Sociedade) no contexto da educação Brasileira. Ensaio Pesquisa em Educação em Ciências, Belo Horizonte, v. 2, n. 2, p. 1-23, dez. 2002.

SASSERON, L. H.; CARVALHO, A. M. P. Almejando a alfabetização científica no ensino fundamental: a proposição e a procura de indicadores do processo. Revista Investigações em Ensino de Ciências, Porto Alegre, v. 13, n. 3, p. 333-352, 2008.

SASSERON, L. H.; CARVALHO, A. M. P. Ensino por CTSA: almejando a Alfabetização Científica no Ensino Fundamental. In: ENCONTRO NACIONAL DE PESQUISA EM EDUCAÇÃO EM CIÊNCIAS, VI, Águas de Lindóia. Anais..., Águas de Lindóia, 2007.

SEPINI, R. P.; CABRAL, S.A., MACIEL, M.D. Ciência/Tecnologia/Sociedade nos conteúdos sobre a origem da vida em livros didáticos de Biologia do Ensino Médio. In: ENCONTRO NACIONAL DE PESQUISA EM EDUCAÇÃO EM CIÊNCIAS, IX, Águas de Lindóia. Anais... Águas de Lindóia, 2013.

SOUSA, R. G.; BRITO, L. P. Controvérsias em experiências pedagógicas CTS/CTSA na formação inicial de professores de ciências: o que dizem algumas dissertações e teses brasileiras? Amazônia: Revista de Educação em Ciências e Matemática, v. 12, n. 23, p. 85-102, jul/dez, 2015.

STRIEDER, R. et al. Educação CTS e Educação Ambiental: ações na formação de professores. Alexandria Revista de Educação em Ciência e Tecnologia, Florianópolis, v.9, n.1, p.57-81, mai. 2016.

STRIEDER, R.; KAWAMURA, M. R. Panorama das pesquisas pautadas por abordagem CTS. In: ENCONTRO NACIONAL DE PESQUISA EM EDUCAÇÃO EM CIÊNCIAS, VII, Florianópolis. Anais... Florianópolis: UFSC, 2009.

TEIXEIRA, R. S.; CICILLINI, G. A. Educação e Saúde, Educação Ambiental e CTS: contribuindo para a formação do cidadão. In: ENCONTRO NACIONAL DE PESQUISA EM EDUCAÇÃO EM CIÊNCIAS, IV, Bauru. Anais... Bauru, 2003.

VIECHENESKI, J. P.; CARLETO, M. R. Ensino de Ciências e Alfabetização Científica nos anos iniciais do Ensino Fundamental: um olhar sobre as escolas públicas de Carambeí. In: 
ENCONTRO NACIONAL DE PESQUISA EM EDUCAÇÃO EM CIÊNCIAS， VIII, Campinas. Anais..., Campinas: UNICAMP, 2011.

VIECHENESKI, J. P.; CARLETTO, M. R. Iniciação à alfabetização científica nos anos iniciais: contribuições de uma sequência didática. Revista Investigações em Ensino de Ciências, v. 18, n. 3, p. 525-543, 2013.

VIECHENESKI, J. P.; CARLETTO, M. R. Sequência didática para o ensino de ciências nos anos iniciais: subsídios para iniciação à alfabetização científica. Revista Dynamis, Blumenau, v. 19, n. 1, p. 3-16, 2013.

VIECHENESKI, J. P.; LORENZETTI, L.; CARLETTO, M.R. Desafios e práticas para o ensino de ciências e alfabetização científica nos anos iniciais do ensino fundamental. Revista Atos de Pesquisa em Educação, Blumenau, v. 7, n. 3, p. 853-876, set/dez. 2012.

VIEIRA, C. T.; VIEIRA, R. M. Construção de práticas didático-pedagógicas com orientação CTS: impacto de um programa de formação continuada de professores de ciências no ensino básico. Revista Ciência \& Educação, Bauru, v. 11, n. 2, p. 191-211, 2005. 